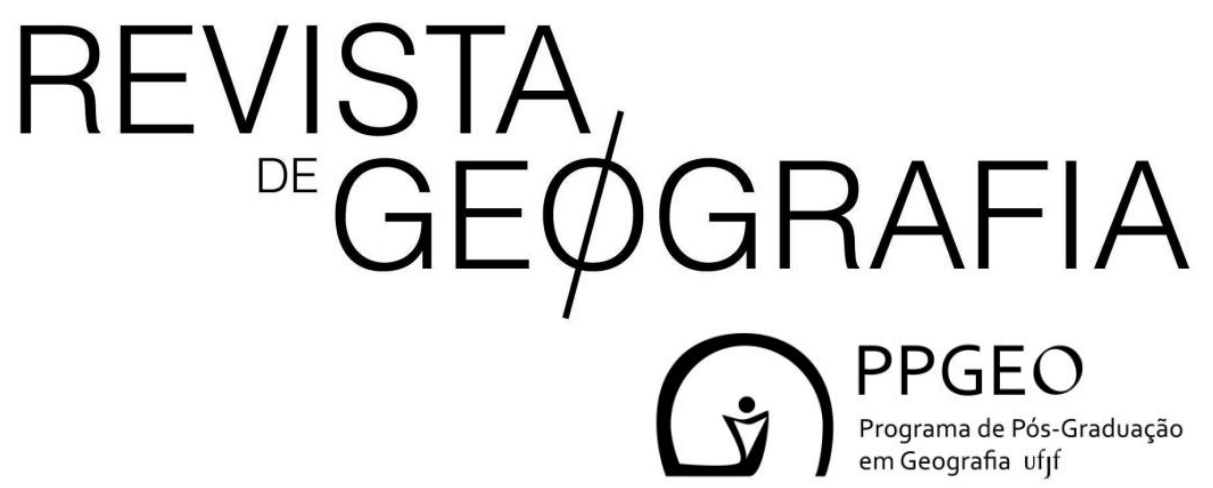

\title{
ESTUDO DA INFLUÊNCIA DA ZONA DE CISALHAMENTO DE TRÊS CORAÇÕES NA OCORRÊNCIA DE VOÇOROCAMENTOS
}

STUDY OF THE INFLUENCE OF THE TRÊS CORAÇÕES SHEAR ZONE IN THE GULLYING OCCURRENCE

Éric Andrade Rezende

Universidade Federal de Ouro Preto Campus Morro do Cruzeiro, s/n - Bauxita Ouro Preto - MG - 35400-000

E-mail: ericrezende@ufmg.br 


\section{Resumo}

O presente estudo visa realizar o mapeamento das ocorrências de voçorocas em uma área do sul de Minas Gerais, localizada entre os municípios de Campanha e Itutinga. Esse mapeamento tem como objetivo estabelecer possíveis relações entre a distribuição espacial dos voçorocamentos e a faixa de influência da Zona de Cisalhamento de Três Corações (ZCTC). A varredura foi realizada em uma faixa de $20 \mathrm{~km}$ de largura utilizando imagens de satélite de alta resolução. As 182 voçorocas identificadas confirmaram a ocorrência de uma significativa concentração dessas feições nas proximidades da faixa tectonizada, embora a distribuição das mesmas não seja homogênea. Os resultados apontam que o controle morfoestrutural não é tão decisivo no desencadeamento de processos de erosão acelerada, já que uma parcela muito reduzida das feições se encontra adaptada à direção da ZCTC (NE-SW). Além disso, apenas $13 \%$ das voçorocas estão inseridas na faixa de maior deformação que possui $1 \mathrm{~km}$ de largura. Por outro lado, as elevadas taxas de incisão fluvial verificadas previamente nas proximidades da ZCTC indicam que há um controle morfotectônico com abrangência espacial mais ampla. A instabilidade da rede drenagem provocada por alterações nos níveis de base repercute em diversas cabeceiras sob a forma de voçorocamentos.

Palavras-chave: erosão acelerada, voçorocas, morfoestrutura, morfotectônica

\section{Abstract}

The present study aims to map the occurrences of gullies in an area of southern Minas Gerais, located between the municipalities of Campanha and Itutinga. This mapping aims to establish possible relationships between the spatial distribution of the gullies and the influence range of the Três Corações Shear Zone (ZCTC). The scan was performed on a 20 $\mathrm{km}$ wide strip using high resolution satellite images. The 182 gullies identified confirmed the occurrence of a significant concentration of these features in the vicinity of the tectonized band, although their distribution is not homogeneous. The results show that the morphostructural control is not so decisive in triggering accelerated erosion processes, since a very small portion of the features are adapted to the direction of the ZCTC (NE-SW). In addition, only $13 \%$ of gullies are inserted in the most deformation strip that is $1 \mathrm{~km}$ wide. On the other hand, the high rates of fluvial incision seen previously in the vicinity of the ZCTC indicate that there is a morphotectonic control with a wider spatial scope. The instability of the drainage network caused by changes in the base levels has repercussions in several headwaters in the form of gullies.

Keywords: accelerated erosion, gullies, morphostructure, morphotectonics

\section{Introdução}

Voçorocas são grandes feições erosivas lineares ou ramificadas, originadas pelo aprofundamento e alargamento de ravinas que atingem o nível freático e assim passam a ser modeladas também pela ação da água subterrânea. (GUERRA, 1995; MELO et al., 2005, SANTORO, 2015). Fatores pedológicos, topográficos, litológicos, climáticos e antrópicos são comumente apontados como os principais condicionantes do voçorocamento (RESENDE, 1985; GUERRA, 1995; VALENTIN et al., 2005; SANTORO, 2015). No entanto,

ISSN: 2236-837X 
alguns estudos têm demonstrado que a influência de fatores morfoestruturais e morfotectônicos pode ser decisiva na formação dessas feições associadas a processos de erosão acelerada (MOREIRA, 1992; HASUI et al.,1995; SANTOS, 1999; BONACCORSI DE CAMPOS, 2006; QUÉNÉHERVÉ et al., 2016). Nesse sentido, Bierman e Montgomery (2014) apontam ainda que diversos voçorocamentos tem sua origem anterior à ocupação humana, o que sugere que se trata de um processo normal de evolução do relevo em determinados terrenos.

De acordo com Saadi (1998), campos de voçorocas em áreas rurais de Minas Gerais se associam a zonas de domeamento crustal e/ou zonas sismogênicas articuladas sobre zonas de cisalhamento reativadas no Neógeno e no Quaternário. A influência de importantes faixas tectonizadas no desencadeamento de processos geomorfológicos no sudeste brasileiro também é ressaltada pelo CPRM (2015), que aponta áreas com alta suscetibilidade a movimentos gravitacionais ao longo da Zona de Cisalhamento do Rio Paraíba do Sul.

Nesse contexto, o presente trabalho visa realizar o mapeamento das ocorrências de voçorocas em uma área do sul de Minas Gerais, localizada entre os municípios de Campanha e Itutinga (Figura 1). Esse mapeamento tem como objetivo estabelecer possíveis relações entre a distribuição espacial dos voçorocamentos e a faixa de influência da Zona de Cisalhamento de Três Corações (ZCTC), pertencente ao Sistema Transcorrente Paraíba do Sul (HASUI, 2012). De acordo com Saadi et al. (2002), essa importante estrutura é parte da Descontinuidade Crustal Alto Rio Grande, que atravessa a área de estudo e controla áreas de erosão acelerada, bem como, escarpas, planícies fluviais e depressões preenchidas por sedimentos cenozoicos.

ISSN: 2236-837X 


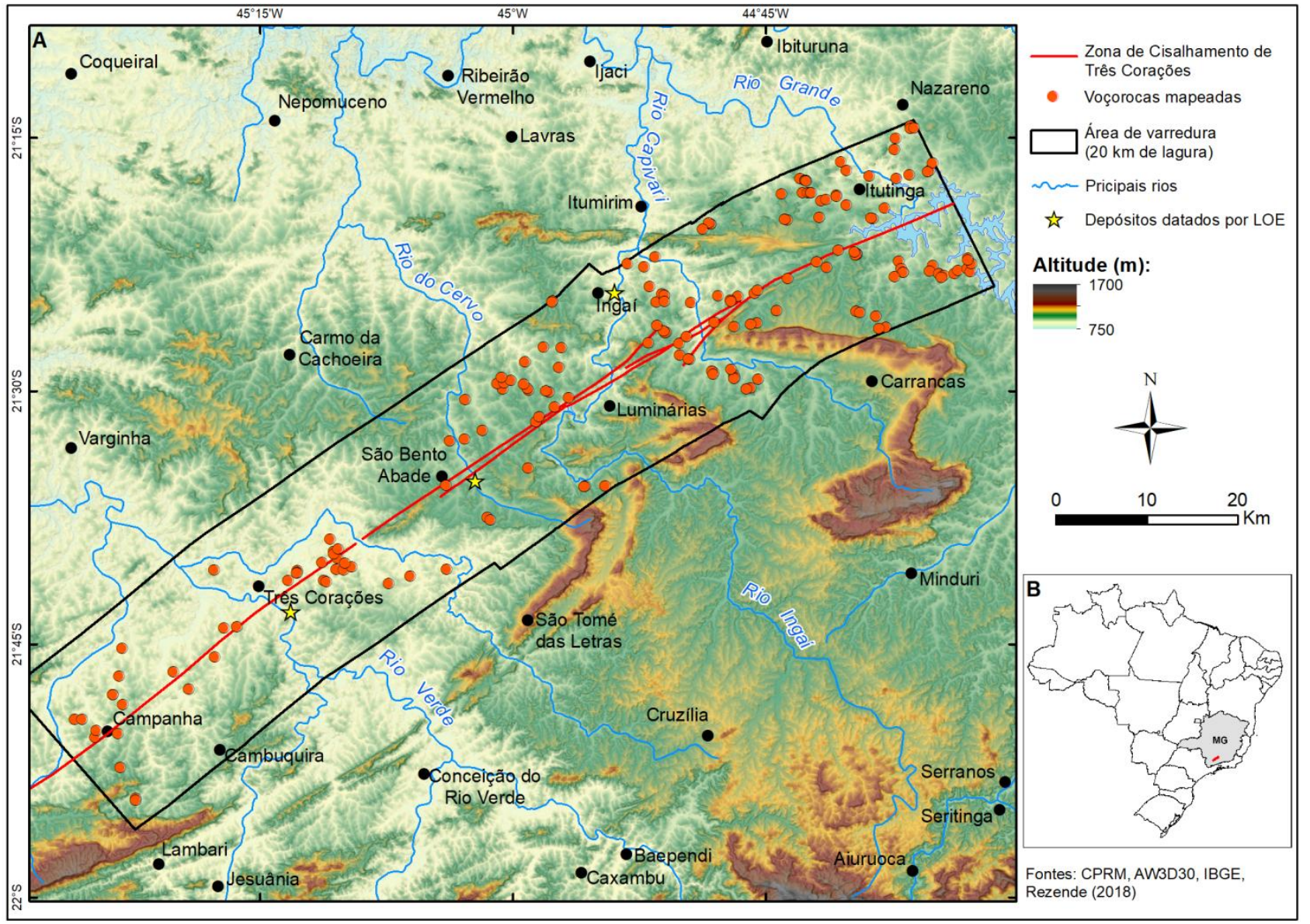

Figura 1. A) Contexto geomorfológico da área de estudo e localização das voçorocas mapeadas ao longo da Zona de Cisalhamento de Três Corações. B) Localização da área de estudo no Brasil e em Minas Gerais.

A localização de depósitos datados por LOE citados no texto foi retirada de Rezende (2018).

Caso se confirme a existência de uma concentração de voçorocamentos ao longo da ZCTC, dois tipos de controle podem ser colocados como hipóteses para explicar o fenômeno: i) controle passivo, através da elevada erodibilidade do manto de alteração gerado a partir das rochas milonitizadas; ii) controle ativo, através da instabilidade da rede de drenagem provocada pela atividade neotectônica. Com base em trabalhos cartográficos, observações de campo e cruzamento com dados gerados em trabalhos anteriores, pretende-se investigar as evidências que apontem ou não para a participação de cada um dos tipos de controle citados no desencadeamento das feições erosivas.

\section{Caracterização da área}

A área de estudo está situada ao sul do Cráton do São Francisco, na zona de interferência entre as faixas Brasília (N-S) e Ribeira (NE-SW), ambas resultantes da Orogênese Brasiliana no Neoproterozoico. A estrutura regional pré-cambriana é dominada por um sistema de nappes cortadas por zonas de cisalhamento regionais subverticais

ISSN: 2236-837X 
destrais de direção NE-SW (TROUW et al., 2003, 2013). O quadro litológico da área é formado por metassedimentos neoproterozoicos do Grupo Andrelândia, representados por paragnaisses, quartzitos, filitos, xistos e anfibolitos, bem como por rochas cristalinas do embasamento paleoproterozoico-arqueano (Figura 2).

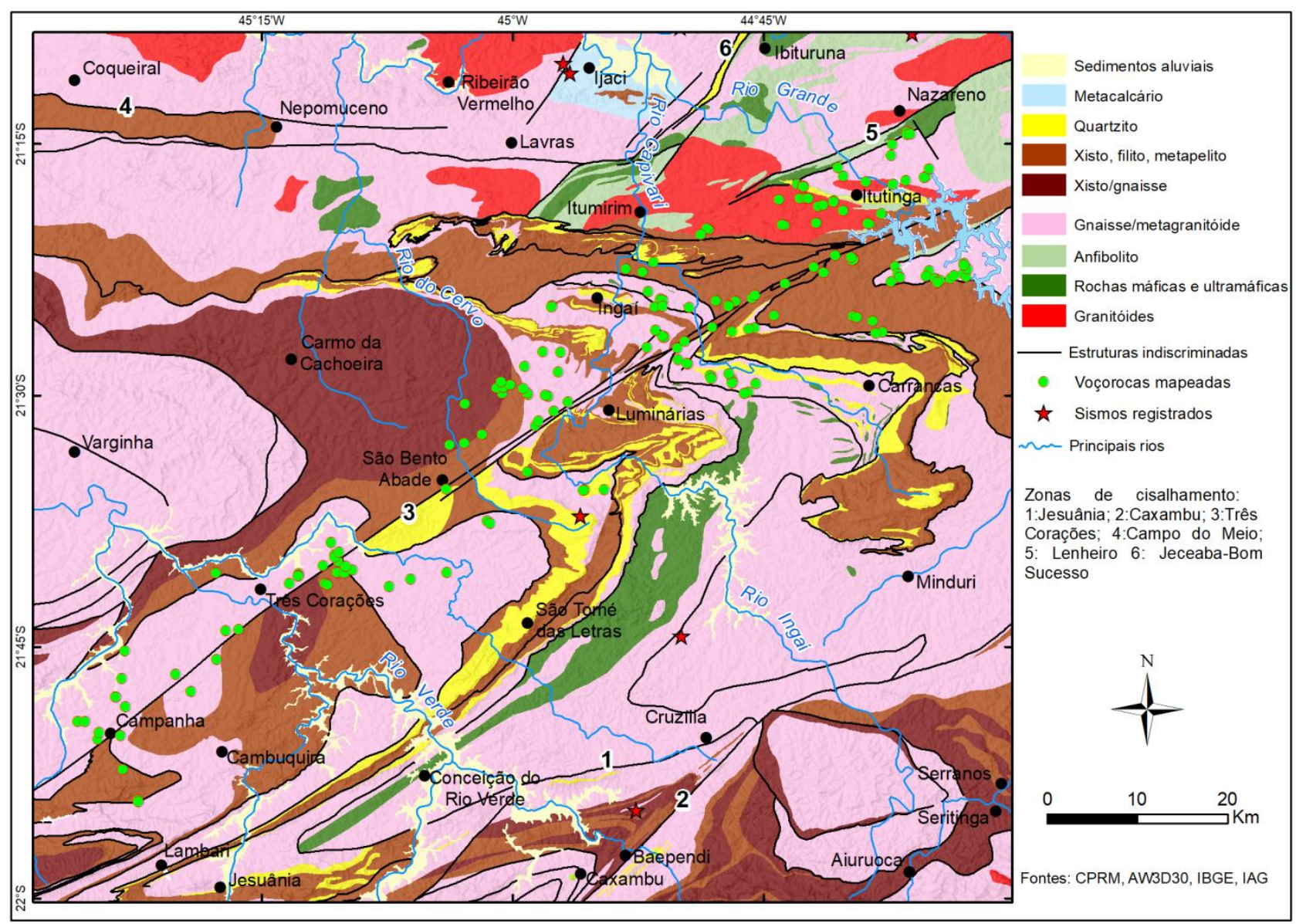

Figura 2. Mapa geológico simplificado com unidades litológicas agrupadas segundo o tipo de rocha predominante.

A ZCTC é parte da Zona Rúptil Carandaí-Mogi-Guaçu, composta por falhas associadas a espessas faixas de ultramilonitos e milonitos, muitas vezes, com larguras quilométricas (WERNICK et al., 1981). De acordo com Almeida (1994) e Peternel et al. (2005), trata-se de uma estrutura subvertical, com direção N60E e mergulhos íngremes para SE, com rejeito oblíquo, mas predominantemente horizontal e deslocamento destral. Sua espessura é de aproximadamente $6 \mathrm{~km}$, embora a faixa de deformação mais intensa, onde ocorrem as estruturas truncadas, a transposição das foliações anteriores e as rochas miloníticas, não passa de $1 \mathrm{~km}$.

Do ponto de vista morfotectônico, a ZCTC está inserida na Descontinuidade Crustal Alto Rio Grande (DCARG), que corresponde a uma linha de fraqueza tectônica herdada do

ISSN: 2236-837X 
Pré-Cambriano, ao longo da qual se concentram expressivas feições neotectônicas. A DCARG possui uma largura aproximada de 5-6 km e traçado retilíneo na direção N60E, entre Ouro Fino e São João del-Rei (SAADI, 1991). Saadi et al. (2002) estimam que a movimentação mais recente da DCARG é holocênica.

O relevo da área resulta principalmente de processos de denudação diferencial. Sobre os gnaisses e xistos, predomina um modelado composto por colinas e morrotes, com topos posicionados entre 900 e $1000 \mathrm{~m}$ de altitude e encostas com declividades entre $10 \%$ e $25 \%$. Já os quartzitos, sustentam cristas que atingem cotas superiores a $1200 \mathrm{~m}$ (Figuras 1 e 2). A rede de drenagem é caraterizada por um padrão predominantemente dendrítico, onde se destacam o Rio Grande e alguns de seus principais afluentes, como os rios Verde, do Cervo e Capivari. O médio curso do Rio Verde estabelece um nível de base inferior ao dos demais rios situados a nordeste, o que se reflete na existência de um compartimento deprimido e mais dissecado circunscrito à sua bacia (REZENDE e CASTRO, 2016).

O clima é tropical de altitude, com duas estações bem definidas, uma chuvosa e quente, de outubro a março e outra seca e amena, de abril a setembro. A precipitação média anual é de cerca de $1600 \mathrm{~mm}$ e a temperatura média anual fica entre $18^{\circ} \mathrm{C}$ e $19^{\circ} \mathrm{C}$ (CARVALHO et al. 2008).

\section{Procedimentos metodológicos}

O mapeamento das feições erosivas foi realizado no software Google Earth, utilizando como base as imagens de satélite de alta resolução disponibilizadas pelo mesmo. Foram mapeadas as voçorocas conectadas à rede drenagem, tanto as ativas quanto as estabilizadas, excluindo-se as paleovoçorocas. A localização das feições foi registrada através de símbolos pontuais que posteriormente foram transferidos para o software ArcGis 10, onde foi possível o cruzamento com mapas geológicos na escala de 1:100.000 (PEDROSA SOARES et al., 2003; TROUW, 2008). A base unificada utilizada no trabalho consta no Mapa Geológico de Minas Gerais (PINTO e SILVA, 2014). De modo a facilitar a verificação de controles litológicos sobre a distribuição das voçorocas, foi feito um agrupamento das unidades litológicas de acordo com o(s) tipo(s) de rocha predominante(s) (Figura 2).

A varredura nas imagens de satélite abrangeu uma faixa de aproximadamente 100 $\mathrm{km}$ de comprimento, entre os municípios de Campanha e Itutinga. A largura total da faixa investigada foi estabelecida em $20 \mathrm{~km}$, incluindo suas ramificações. Esse valor foi definido

ISSN: 2236-837X 
tendo como base a espessura máxima da zona de cisalhamento, estimada por Saadi (1991) e Almeida (1994) em aproximadamente $6 \mathrm{~km}$.

Para a análise do controle estrutural foram traçados lineamentos ao longo do talvegue de maior desenvolvimento de cada voçoroca. Esse procedimento também foi realizado sobre imagens de satélite de alta resolução no interior da faixa de $6 \mathrm{~km}$ de largura ao longo da ZCTC. Nas feições onde há inflexões ou ramificações de grande porte ao longo de direções distintas foram traçados dois ou mais lineamentos. As direções foram exportadas por meio do script AzimuthFinder 1.1 (QUEIROZ et al. 2014) no ArcGis 10 e as rosetas de frequência foram produzidas através do aplicativo OpenStereo.

O quadro neotectônico regional definido com base na análise de planos de falhas em sedimentos neogênicos e saprólitos foi obtido nos trabalhos de Saadi (1991), Costa (1999), Santos (1999) e Morales e Hasui (2003). Também foram utilizadas taxas de incisão calculadas por Rezende (2018) a partir da datação de antigos depósitos fluviais por luminescência opticamente estimulada (LOE). A localização dos depósitos datados nos vales dos rios Verde, do Cervo e Ingaí consta na Figura 1.

Trabalhos de campo com foco na porção setentrional da ZCTC foram realizados para visualização do modo como as voçorocas se inserem na paisagem ao longo da estrutura. Também foram observados a profundidade e o grau de desenvolvimento das feições erosivas, além da existência de possíveis ações antrópicas que possam ter contribuído com o voçorocamento.

\section{Resultados e discussões}

Um total de 182 voçorocas foram identificadas na varredura em imagens de satélite dentro de uma faixa de $20 \mathrm{~km}$ de largura, o que resulta em uma densidade de 0,08/ $\mathrm{km}^{2}$. No interior da faixa de $6 \mathrm{~km}$ referente à espessura máxima da zona de cisalhamento (incluindo suas ramificações) foram mapeadas 72 voçorocas $\left(0,10 / \mathrm{km}^{2}\right)$, correspondentes a $40 \%$ do total. Já na faixa de $1 \mathrm{~km}$, referente à área de maior deformação (ALMEIDA, 1994; BITTENCOURT, 2010), encontram-se 23 voçorocas $\left(0,16 / \mathrm{km}^{2}\right)$, que perfazem $13 \%$ do total.

Com base no mapa da Figura 1 é possível notar uma significativa ocorrência de voçorocas ao longo da faixa de direção NE-SW correspondente à ZCTC. Contudo, a concentração de feições erosivas não é generalizada e homogeneamente distribuída ao longo da estrutura. Segmentos com maior densidade se alternam com outros menos afetados por voçorocamentos. De modo geral, é possível notar que a metade nordeste da

ISSN: 2236-837X 
faixa que envolve a ZCTC reúne um número maior de voçorocas do que sua metade sudoeste.

A área com menor concentração de voçorocas corresponde ao entorno da cidade de São Bento Abade, onde predominam colinas com declividades reduzidas $(<15 \%)$ em relação à maior parte do restante da faixa de influência da zona de cisalhamento. Por outro lado, as áreas com maiores concentrações estão situadas a nordeste de Três Corações, a oeste de Luminárias, a leste de Ingaí e no entorno de Itutinga.

Do ponto de vista do controle litológico, as voçorocas se distribuem por todas as unidades litoestratigráficas mapeadas na área, exceto aquelas com presença significativa de quartzitos (formações São Tomé das Letras e Campestre). As principais concentrações de voçorocas estão sobre unidades compostas predominantemente por paragnaisses e xistos, como as formações São Vicente e Santo Antônio, bem como sobre granitoides e ortognaisses situados no norte da área. A Figura 2 evidencia a ampla distribuição dos voçorocamentos sobre todas as litologias que permitem a formação de um manto de alteração relativamente espesso devido à sua composição mineralógica. Cabe mencionar que sobre os paragnaisses e xistos da área comumente se desenvolvem Latossolos (UFV CETEC - UFLA - FEAM, 2010), uma classe de solo geralmente caracterizada por uma baixa erodibilidade natural (RESENDE et al., 2014). Portanto, a exposição do horizonte C (saprólito) pouco coeso durante a retração de cabeceiras de drenagem é fundamental para que voçorocamentos se desenvolvam em tais solos (RESENDE, 1985; SAMPAIO et al. 2016).

A destacada ocorrência de voçorocas no interior da faixa de $20 \mathrm{~km}$ ao longo da ZCTC sugere que, de fato, há influência da faixa tectonizada sobre o desencadeamento de processos erosivos lineares. Desse modo, a relação entre campos de voçorocas e zonas transcorrentes no sul de Minas Gerais, já observada por Saadi $(1991,1998)$ e Santos (1999), é novamente evidenciada pelos dados do presente estudo. Em um primeiro momento, dois tipos de controle podem ser cogitados para explicar essa influência da ZCTC na ocorrência de processos erosivos acelerados nas cabeceiras: controle passivo de natureza morfoestrutural e controle ativo de natureza morfotectônica.

O controle passivo atuaria através da elevada erodibilidade do manto de alteração gerado a partir das rochas intensamente deformadas pela zona de cisalhamento, bem como pelo condicionamento dos fluxos de água superficiais e subsurperficiais. Nas proximidades de uma falha comumente ocorrem milonitos e brechas que, em geral, são materiais bastante suscetíveis à erosão e favorecem a instalação de vales retilíneos (SUGUIO, 2010). Ao longo da ZCTC, a foliação regional de baixo mergulho é reorientada e verticalizada

ISSN: 2236-837X 
paralelamente à zona de cisalhamento (BITTENCOURT, 2010), o que tenderia a facilitar o entalhamento erosivo nos saprólitos segundo as linhas de fraqueza herdadas das rochas sãs. Caso esse controle estrutural fosse efetivo, as voçorocas integrariam um padrão de drenagem paralelo orientado na direção NE-SW. Além disso, seria esperado uma concentração expressiva de voçorocas no interior da faixa de maior deformação com espessura máxima de $1 \mathrm{~km}$ (ALMEIDA, 1994; BITTENCOURT, 2010). No entanto, o mapeamento das feições erosivas demonstrou que essas premissas não se manifestam de forma efetiva na área de estudo.

É muito comum que nas proximidades da ZCTC as voçorocas se desenvolvam em direção ortogonal ou oblíqua à estrutura, conforme lustra a Figura 3. No diagrama de rosetas (Figura 4A) referente às voçorocas situadas no interior da faixa de $1 \mathrm{~km}$ de largura se destaca a direção submeridiana NNE e, em menor medida, a direção ENE. Vale ressaltar que os azimutes entre $55^{\circ}$ e $68^{\circ}$, nos quais se inserem a maioria dos traços mapeados da ZCTC, são pouco representativos em frequência de voçorocas. O quadrante NW também não concentra ocorrências em nenhuma faixa especifica de azimutes. Além disso, apenas 23 feições (13\%) estão nessa faixa central, o que indica que a ZCTC exerce um controle morfoestrutural relativamente pouco efetivo sobre as voçorocas.

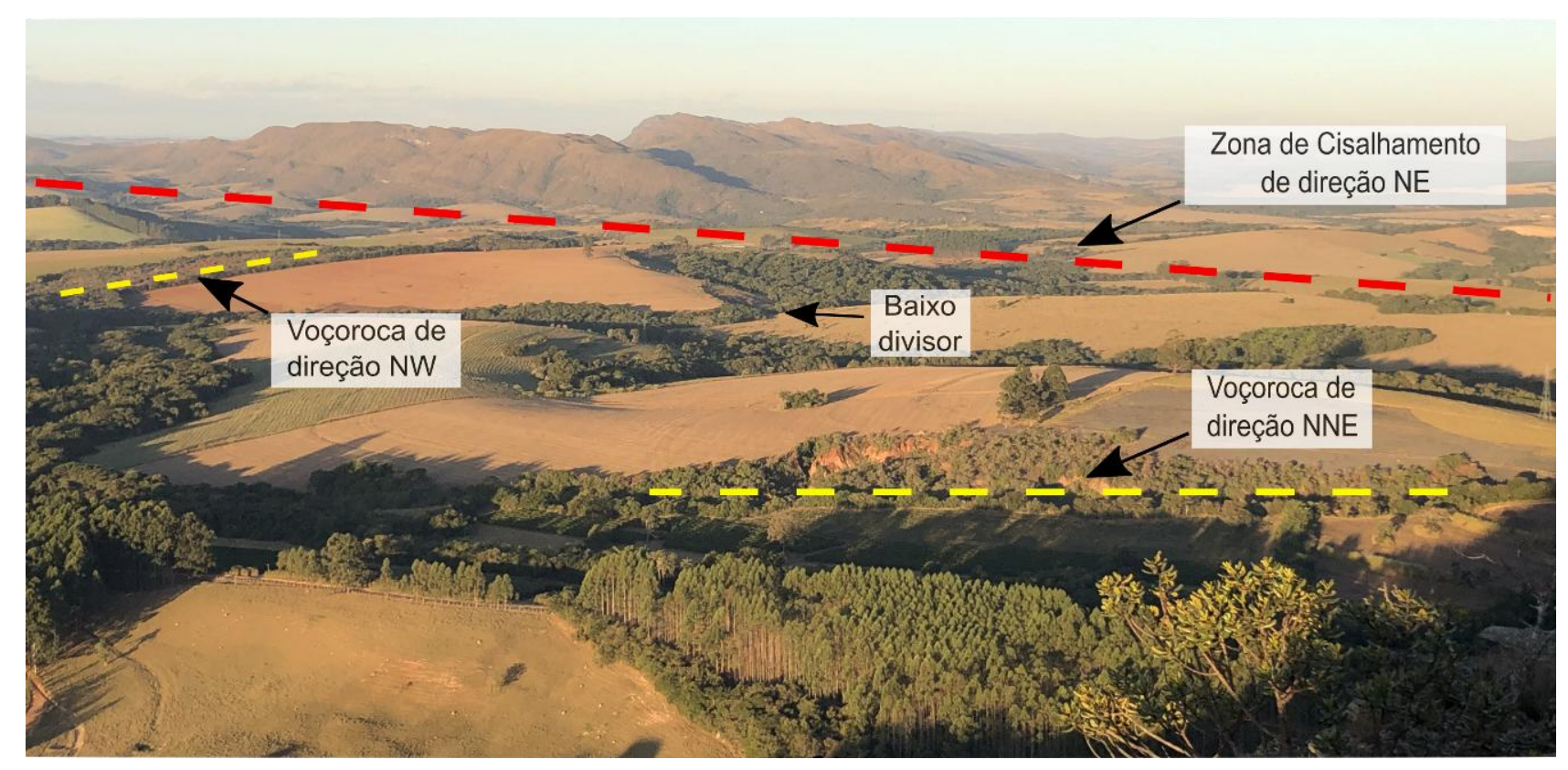

Figura 3. Visão de um segmento da faixa de maior deformação da zona de cisalhamento. A imagem mostra duas voçorocas com direção discordante da estrutura, além de uma anomalia de drenagem representada por um baixo divisor. Vista para ENE a partir da Serra Negra, em Ingaí. Ao fundo serras do Galinheiro (ou dos Coelhos) e de Carrancas.

O traçado aproximado da ZCTC foi feito com base no mapa geológico da folha Lavras (QUÉMÉNEUR et al., 2003) e desconsiderou suas ramificações locais. 


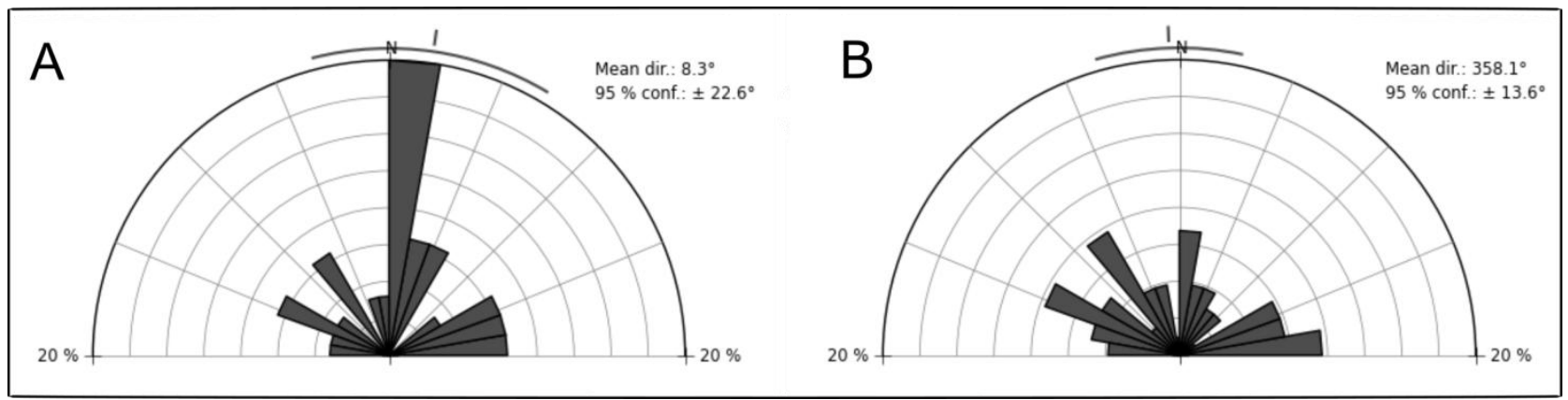

Figura 4. Diagramas de rosetas com a frequência das direções preferenciais de desenvolvimento das voçorocas (intervalos de $10^{\circ}$ ).

A) Voçorocas localizadas no interior da faixa de $1 \mathrm{~km}$ de largura ao longo da ZCTC. B) Voçorocas localizadas no interior da faixa de $6 \mathrm{~km}$ de largura ao longo da ZCTC.

Considerando todas as voçorocas inseridas na faixa de $6 \mathrm{~km}$ ao longo da ZCTC, a direção NNE perde importância relativa, enquanto o quadrante NW se torna um pouco mais representativo (Figura 4B). Os lineamentos com azimutes próximos a 60 continuam pouco numerosos, o que confirma o fraco controle estrutural no desenvolvimento das voçorocas também fora da faixa de maior deformação. Esse cenário difere do que ocorre a leste da área de estudo, onde Santos (1999) observou um forte controle estrutural de voçorocas por zonas de falha ENE a NE também pertencentes ao Sistema Transcorrente Paraíba do Sul.

De modo geral, há uma tendência da ocorrência de voçorocas diminuir nas áreas mais afastadas da faixa central da zona de cisalhamento. No entanto, o número significativo de feições erosivas mapeadas para além da faixa de maior deformação sugere a atuação de um fator controlador com abrangência espacial mais ampla, como a instabilidade tectônica quaternária ao longo da DCARG. Tal hipótese vai de encontro à afirmação de Saadi (1998), segundo a qual os campos de voçorocas mineiros estão associados a zonas de cisalhamento reativadas. Santos (1999) também ressalta que a movimentação ligada à atividade neotectônica no Planalto do Alto Rio Grande se dá preferencialmente através da reativação dos grandes traços transcorrentes pretéritos. Nesse contexto, a tectônica neoquaternária ao longo da ZCTC pode ter induzido uma intensa erosão regressiva, desestabilizando o perfil de equilíbrio dos cursos fluviais e provocando o desenvolvimento de voçorocas nas cabeceiras, sem que as mesmas apresentem uma direção preferencial de desenvolvimento. Conforme apontam Quénéhervé et al. (2016), os sistemas de voçorocas podem ser indicativos da atividade tectônica como um dos seus fatores desencadeadores, já que mudanças de nível de base provocam respostas nos processos erosivos a montante.

A instabilidade crustal na área e sua repercussão na rede drenagem são indicadas por taxas de incisão extremamente elevadas no Rio Grande e em seus principais afluentes que cortam a ZCTC, conforme apontam datações de depósitos fluviais por luminescência opticamente estimulada realizadas por Rezende (2018). Datações de sedimentos

ISSN: 2236-837X 
localizados nas proximidades da ZCTC e inseridos nos vales dos rios Verde, do Cervo e Ingaí (Figura 1), forneceram taxas de incisão fluvial aproximadas de $2.010 \mathrm{~mm} / \mathrm{ka}, 252$ $\mathrm{mm} / \mathrm{ka}$ e $487 \mathrm{~mm} / \mathrm{ka}$, respectivamente. Todas essas taxas podem ser consideradas anômalas para um ambiente intraplaca. O rebaixamento dos níveis de base regionais, necessário para um entalhamento tão acelerado nos últimos milhares de anos, repercute nas cabeceiras à medida que as vagas erosivas se propagam para montante.

O regime transcorrente, associado a compressão NW-SE e distensão NE-SW, atualmente ativo na área (SAADI, 1991; COSTA, 1999; SANTOS, 1999; MORALES e HASUI, 2003), é o provável mecanismo responsável por induzir o rebaixamento dos níveis de base e assim estimular um progressivo ajuste da rede drenagem em direção às cabeceiras. O rebaixamento do nível de base provocado por um soerguimento regional se expressa também na espeleogênese em quartzitos nas serras de Luminárias e Carrancas, como apontam Correa Neto et al. (1996). O controle sobre a sedimentação quaternária, as escarpas retilíneas e as anomalias de drenagem são alguns dos elementos indicativos de atividade neotectônica que ocorrem ao longo da ZCTC, principalmente em sua metade nordeste. Merece destaque a ocorrência de baixos divisores hidrográficos (Figura 3) que, inclusive, podem ser resultantes da coalescência de antigas voçorocas hoje já completamente erodidas.

Conforme apontado por Resende (1985), as voçorocas podem evoluir rapidamente por solapamento sobre o material pouco coeso de um horizonte $\mathrm{C}$ profundo. $\mathrm{Na}$ área de estudo, a disponibilidade de material inconsolidado representado pelo manto de alteração nas cabeceiras permite que a incisão fluvial resultante de um rebaixamento do nível de base se manifeste através de voçorocamentos. Entre as feições erosivas visitadas em campo, em apenas uma, situada no leste do município de Ingaí, o material erodido é de natureza sedimentar aluvial. Nas demais, predominam profundos saprólitos friáveis (horizonte $\mathrm{C}$ ), recobertos ou não por um solum (horizontes $\mathrm{A}$ e B) de espessura variável. Já nos segmentos fluviais a jusante das voçorocas predomina a ocorrência de leito rochoso.

$\mathrm{Na}$ extremidade nordeste da ZCTC, os arredores de Itutinga e Nazareno abrigam uma das maiores concentrações de voçorocas da área estudada (Figuras 1 e 2). A intensa recorrência de processos erosivos se prolonga ainda em direção a nordeste até São João del-Rei, conforme apontam Silva e Ferreira (2014). Essa região sofre influência da zona de cisalhamento Nazareno-São João del-Rei (QUÉMÉNEUR et al., 2003) ou do Lenheiro (TEIXEIRA et al. 2008), que ocorre paralela à ZCTC e também integra a DCARG. As evidências de atividade neotectônica ao longo dessa segunda estrutura são amplamente referenciadas na literatura (SAADI, 1991; COSTA, 1999; SAADI et al., 2002; MORALES e

ISSN: 2236-837X 
HASUI, 2003; REZENDE e CASTRO, 2016), o que corrobora a hipótese de um controle morfotectônico no desencadeamento de voçorocamentos. Na bacia do Rio Santo Antônio, localizada pouco ao norte da zona de cisalhamento do Lenheiro, Moreira (1992) também atribuiu à instabilidade tectônica um papel fundamental na ocorrência de voçorocas. Tratase, portanto, de um mecanismo de expressão regional que afeta as bacias de afluentes do alto Rio Grande seccionados por estruturas do Sistema Transcorrente Paraíba do Sul ativas no Neoquaternário.

Por fim, é importante mencionar que ao mecanismo morfotectônico atuante em escala regional se somam fatores controladores de ordem local, que podem intensificar ou não a tendência de que voçorocamentos se desenvolvam na área. Ferreira et al. (2011) e Sampaio et al. (2016), por exemplo, destacam o papel da influência antrópica e dos atributos do solo na formação de voçorocas em Nazareno, município localizado na extremidade nordeste da faixa de influência da ZCTC. O fator antrópico, associado principalmente ao desmatamento, à abertura de estradas e valas divisórias de propriedades e à mineração, atua em uma escala temporal menor, restrita às últimas centenas de anos.

\section{Considerações finais}

O mapeamento de voçorocas ao longo da ZCTC confirmou a ocorrência de uma significativa concentração de feições erosivas nas proximidades da estrutura, embora a distribuição das mesmas não seja homogênea.

Os resultados apontam que o controle morfoestrutural não é tão decisivo no desencadeamento de processos de erosão acelerada, apesar de algumas das voçorocas estarem adaptadas à direção da ZCTC. Caso a alteração das rochas milonitizadas resulte em saprólitos com maior predisposição à erosão linear, isso não se manifesta através de uma adaptação predominante dos voçorocamentos à direção da faixa tectonizada.

Por outro lado, as elevadas taxas de incisão fluvial verificadas nas proximidades da ZCTC indicam que um controle morfotectônico, com abrangência espacial mais ampla, é a hipótese que apresenta as evidências mais fortes. A dinâmica crustal controla a estabilidade dos níveis de base regionais e, consequentemente, a intensidade da dissecação fluvial. $\mathrm{Na}$ área de estudo, a instabilidade da rede drenagem repercute nas cabeceiras muitas vezes sob a forma de voçorocamentos. Nesse contexto, as descontinuidades tectônicas herdadas do pré-cambriano, em especial as zonas de cisalhamento pertencentes ao Sistema Transcorrente Paraíba do Sul, se mostram como locais preferenciais para

ISSN: 2236-837X 
desencadeamento de processos erosivos lineares em resposta à mobilidade crustal neoquaternária.

Muitas vezes tratados apenas como resultantes da ação antrópica, os campos de voçorocas na verdade podem representar importantes elementos indicadores de fases de instabilidade morfodinâmica desencadeadas pela atividade neotectônica ou por perturbações morfoclimáticas. Os voçorocamentos constituem processos naturais na evolução de cabeceiras que são favorecidos ou não por condicionantes de ordem litoestrutural e pedológica. As intervenções antrópicas, principalmente através da retirada da cobertura vegetal, podem atuar como elemento catalisador. Desse modo, aspectos morfoestruturais e morfotectônicos não devem ser negligenciados no estudo e no manejo de áreas afetadas por erosão acelerada.

\section{Referências Bibliográficas}

ALMEIDA, J. C. H. Caracterização Geométrica do Rejeito da Zona de Cisalhamento de Três Corações, Sul de Minas Gerais. In: CONGRESSO BRASILEIRO DE GEOLOGIA, 38, 1994, Balneário de Camboriú. Anais..., Balneário de Camboriú: SBG-RJ, 1994. v. 2, p. 248-249.

BIERMAN, P. R.; MONTGOMERY, D. R. Key concepts in geomorphology. New York: W. H. Freeman and Company Publishers, 2014. 494 p.

BITTENCOURT, B. R. Caracterização da zona de cisalhamento de Três Corações entre as cidades de Luminárias e São Gonçalo do Sapucaí, sul de Minas Gerais. 2010. 53 f. Trabalho de Conclusão de Curso, Universidade Federal do Rio de Janeiro, Rio de Janeiro, 2010. Disponível em: http://hdl.handle.net/11422/4317. Acesso em: 20 jan. 2021.

BONACCORSI-CAMPOS, M. I. Caracterização da deformação frágil e sua relação com os processos de voçorocamento na porção sudeste do Complexo Metamórfico Bação Quadrilátero Ferrífero - Minas Gerais. 2006. 157 f. Dissertação (Mestrado em Evolução Crustal e Recursos Naturais) - Universidade Federal de Ouro Preto, Ouro Preto, 2006. Disponível em: http://www.repositorio.ufop.br/handle/123456789/3338. Acesso em: 20 jan. 2021.

CARVALHO, L.G.; OLIVEIRA, M.S.; ALVES, M.C.; VIANELLO, R.L.; SEDIYAMA, G.C.; CASTRO NETO, P.; DANTAS, A.A.A. Clima. In: SCOLFORO, J.R.S.; CARVALHO, L.M.T.; OLIVEIRA, A.D. (eds). Zoneamento Ecológico-Econômico de Minas Gerais: Componentes geofísico e biótico. Lavras: Universidade Federal de Lavras, 2008. p. 89-102.

CORRÊA NETO, A. V., DUTRA, G., BAPTISTA FILHO, J. Espeleogênese em quartzitos: comparações entre as zonas de Ibitipoca, Luminárias e Carrancas (MG). CONGRESSO BRASILEIRO DE GEOLOGIA, 38, 1996, salvador. Anais do... Salvador: SBG, 1996, vol. 4, p. 555558.

CPRM - Serviço Geológico do Brasil. Carta de suscetibilidade a movimentos gravitacionais de massa e inundação: município de Barra do Piraí - RJ. Rio de Janeiro, 2015. 1 mapa, color. Escala 1:60.000. Disponível em: http://rigeo.cprm.gov.br/sspui/handle/doc/15039. Acesso em: 20 jan. 2021.

FERREIRA, V. M.; SILVA, M. L. N.; CURI, N.; OLIVEIRA, A. H.; SILVA, M. A.; AVANZI, J. C. Influência antrópica e atributos de solo: inter-relações em ambientes de voçorocas na mesorregião Campos das Vertentes, MG. Geografia, v. 36, n. 1, p. 209-219, 2011. Disponível em:

ISSN: 2236-837X 
https://www.periodicos.rc.biblioteca.unesp.br/index.php/ageteo/article/view/4915/5144. Acesso em: 20 jan. 2021.

GUERRA, A. J. T. Processos Erosivos nas Encostas. In: GUERRA, A. J. T.; CUNHA, S. B. Geomorfologia: uma atualização de bases e conceitos. 2.ed. Rio de Janeiro: Bertrand Brasil, 1995, p. 149-209.

HASUI, Y.; FACINCANI, E. M.; SANTOS, M.; JIMENEZ RUEDA, J. R. Aspectos estruturais e neotectônicos na formação de boçorocas na região de São Pedro, SP. Geociências (UNESP), São Paulo, v. 14, n. 2, p. 59-76, 1995.

HASUI, Y. Sistema Orogênico Mantiqueira. In: HASUI, Y.; CARNEIRO, C. D. R.; ALMEIDA, F. F. M.; BARTORELLI, A. (org.) Geologia do Brasil. São Paulo: Beca, 2012, p. 331-610.

MELO, M. S.; CLAUDINO-SALES, V.; PEULVAST, J.; SAADI, A.; MELLO, C. L. Processos e produtos morfogenéticos continentais. In: SOUZA, C. R. G.; SUGUIO, K.; OLIVEIRA, A. M. S.; OLIVEIRA, P. E. Quaternário do Brasil. São Paulo: ABEQUA/Holos, p. 258-275, 2005.

MORALES, N.; HASUI, Y. Neotectônica na região de Tiradentes - MG. In: Simpósio Nacional de Estudos Tectônicos. 2003, Búzios, Boletim, p 284-285.

MOREIRA, C. V. R. Fatores condicionantes das voçorocas na sub-Bacia do Rio Santo Antônio, Bacia do Rio Grande, MG. 1992. 163 f. Dissertação (Mestrado em Geografia) - Instituto de Geociências, Universidade Federal de Minas Gerais, Belo Horizonte, 1992.

PEDROSA-SOARES, A.C.; NOCE, C.M.; TROUW, R.; HEILBRON, M. Geologia e Recursos Minerais do Sudeste Mineiro. Projeto Sul de Minas - Etapa I (COMIG-UFMG-UFRJ UERJ). Belo Horizonte: COMIG, 2003.

PETERNEL, R.; TROUW, R. A. J.; SCHMITT, R. S. Interferência entre duas faixas móveis neoproterozóicas: 0 caso das faixas Brasília e Ribeira no Sudeste do Brasil. Brazilian Journal of Geology, v. 35, n. 3, p. 297-310, 2005. Disponível em: http://ppegeo.igc.usp.br/index.php/rbg/article/view/9410/9660. Acesso em: 20 jan. 2021.

PINTO C. P.; SILVA M. A. Mapa Geológico do Estado de Minas Gerais. Codemig/CPRM, 2014. Disponível em: http://rigeo.cprm.gov.br/jspui/handle/doc/20786. Acesso em: 20 jan. 2021.

QUEIROZ, G. L.; SALAMUNI, E.; NASCIMENTO, E. R. AzimuthFinder: ferramenta para a extração de dados e apoio na análise estrutural. Geologia USP. Série Científica, v. 14, n. 1, p. 69-80, 2014. Disponível em: http://dx.doi.org/10.5327/Z1519-874X201400010005. Acesso em: 20 jan. 2021.

QUÉMÉNEUR, J. J. G., RIBEIRO, A., TROUW R. A. J., PACIULLO F. V. P., HEILBRON, M. Geologia da Folha Lavras. In: PEDROSA SOARES, A. C.; NOCE, C. M.; TROUW, R. A. J.; HEILBRON, M. (Org.). Geologia e Recursos Minerais do Sudeste Mineiro, Projeto Sul de Minas- Etapa I. Belo Horizonte: COMIG - Companhia Mineradora de Minas Gerais, 2003. CD-ROM.

QUÉNÉHERVÉ, G.; MAERKER, M.; ZAKERINEJAD, R. The Role of Morphotectonics in Gully Formation: Two Case Studies in Semiarid Areas. EGUGA, p. EPSC2016-16505, 2016. Disponível em: https://meetingorganizer.copernicus.org/EGU2016/EGU2016-16505.pdf. Acesso em: 20 jan. 2021.

RESENDE, M.; CURI, N.; REZENDE, S. B.; CORRÊA, G. F.; KER, J. C. Pedologia: Base para distinção de ambientes. 6. ed. Lavras: Editora UFLA, 2014. 378 p.

RESENDE, M. Aplicações de conhecimentos pedológicos à conservação de solos. Informe Agropecuário, Belo Horizonte, MG, v. 11, n. 128, p. 3-18, 1985.

ISSN: 2236-837X 
REZENDE, E. A. O papel da dinâmica espaço-temporal da rede hidrográfica na evolução geomorfológica da alta/média bacia do Rio Grande, sudeste brasileiro. 2018. $194 \mathrm{f}$. Tese (Doutorado em Evolução Crustal e Recursos Naturais) - Escola de Minas, Universidade Federal de Ouro Preto, Ouro Preto, 2018. Disponível em: http://www.repositorio.ufop.br/handle/123456789/9679. Acesso em: 20 jan. 2021.

REZENDE, E. A.; CASTRO, P. T. A. Variação espacial e condicionantes do entalhamento fluvial na bacia do Rio Grande, sul de Minas Gerais. Revista Brasileira de Geomorfologia, v. 17, p. 645-659, 2016. Disponível em: http://dx.doi.org/10.20502/rbg.v17i4.1045. Acesso em: 20 jan. 2021.

SAADI, A. Ensaio Sobre a Morfotectônica de Minas Gerais - tensões intra-placa, descontinuidades crustais e morfogênese. 1991. 285 f. Tese (Prof. Titular) - Instituto de Geociências, Universidade Federal de Minas Gerais, Belo Horizonte, 1991.

SAADI, A. Modelos Morfogenéticos e Tectônica Global: reflexões conciliatórias. Geonomos, v. 6, n. 1, p. 55-63, 1998. Disponível em: https://doi.org/10.18285/geonomos.v6i2.170. Acesso em: 20 jan. 2021.

SAADI, A.; MACHETTE, M. N.; HALLER, K. M.; DART, R. L.; BRADLEY, L.; SOUZA, A. M. P. D. Map and Database of Quaternary Faults and Lineaments in Brazil. Denver: USGS, 2002. 59 p. Disponível em: https://pubs.usgs.gov/of/2002/ofr-02-230/OFR-02-230-508text.pdf. Acesso em: 20 jan. 2021.

SAMPAIO, L. D. F.; OLIVEIRA, M. P. P. D.; CASSARO, R.; RODRIGUES, V. G. S.; PEJON, O. J.; SíGOLO, J. B.; FERREIRA, V. Gully erosion, land uses, water and soil dynamics: a case study of Nazareno (Minas Gerais, Brazil). Dyna, v. 83, n. 199, p. 198-206, 2016. Disponível em: http://dx.doi.org/10.15446/dyna.v83n199.54843. Acesso em: 20 jan. 2021.

SANTORO, J. Erosão continental. In: TOMINAGA, L. K.; SANTORO, J.; AMARAL, R. Desastres naturais: conhecer para prevenir. 3 ed. São Paulo: Instituto geológico, 2015. 196 p. Disponível em: http://www.sidec.sp.gov.br/defesacivil/media/OSDownloads/1438375861 DesastresNaturais.pdf.

Acesso em: 20 jan. 2021.

SANTOS, M. Serra da Mantiqueira e Planalto do Alto Rio Grande: a bacia terciária de Aiuruoca e evolução morfotectônica. 1999. 134 f. Tese (Doutorado em Geociências) - Instituto de Geociências e Ciências Exatas, Universidade Estadual Paulista, Rio Claro, 1999.

SILVA, T. A.; FERREIRA, M. F. M. Análise dos processos erosivos lineares - ravinas e voçorocas entre os municípios de Nazareno e São João Del Rei. In: SIMPÓSIO MINEIRO DE GEOGRAFIA, 1, 2014, Alfenas. Anais... Alfenas, 2014. Disponível em: https://www.unifalmg.edu.br/simgeo/system/files/anexos/Tha\%C3\%ADs\%20Aparecida\%20Silva.pdf. Acesso em: 26 jan. 2021.

SUGUIO, K. Geologia do Quaternário e mudanças ambientais. São Paulo: Oficina de textos, 2010.

TEIXEIRA, W.; ÁVILA, C. A.; NUNES, L. C. Nd-Sr isotopic geochemistry and U-Pb geochronology of the Fé granitic gneiss and Lajedo granodiorite: implications for paleoproterozoic evolution of the mineiro belt, southern São Francisco Craton, Brazil. Geologia USP. Série Científica, v. 8, n. 1, p. 5374, 2008. Disponível em: https://doi.org/10.5327/Z1519-874x2008000100005. Acesso em: 21 jan. 2021.

TROUW R. A. J., RIBEIRO A., PACIULlO F. V. P. Geologia da Folha Caxambu. In: PEDROSASOARES, A.C.; NOCE, C.M.; TROUW, R.; HEILBRON, M. Projeto Sul de Minas- Etapa I. Belo Horizonte: COMIG, 2003. p. 120-152.

TROUW, R. A. J. (Coord.). Geologia da folha Varginha SF.23-V-D-VI: escala 1:100.000. Brasília: CPRM, 
http://rigeo.cprm.gov.br/xmlui/bitstream/handle/doc/10465/Mapa Varginha.pdf. Acesso em: 21 jan. 2021.

TROUW, R. A J.; PETERNEL, R.; RIBEIRO, A.; HEILBRON, M.; VINAGRE, R.; DUFFLES, P.; TROUW, C. C.; FONTAINHA, M.; KUSSAMA, H. H. A new interpretation for the interference zone between the southern Brasília belt and the central Ribeira belt, SE Brazil. Journal of South American Earth Sciences, v. 48, p. 43-57, 2013. Disponível em: https://doi.org/10.1016/i.jsames.2013.07.012. Acesso em: 21 jan. 2021.

UFV - CETEC - UFLA - FEAM. Mapa de solos do Estado de Minas Gerais. Belo Horizonte: Fundação Estadual do Meio Ambiente, 2010. Disponível em: http://www.feam.br/-qualidade-do-solo-e-areascontaminadas/mapa-de-solos. Acesso em: 21 jan. 2021.

VALENTIN, C.; POESEN, J.; LI, Y. Gully erosion: impacts, factors and control. Catena, v. 63, n. 2-3, p. 132-153, 2005. Disponível em: https://doi.org/10.1016/j.catena.2005.06.001. Acesso em: 21 jan. 2021.

WERNICK, E.; FIORI, A.P.; BETTENCOURT, J.S.; CHOUDHOURI, A. A tectônica rígida do fim do Ciclo Brasiliano e sua implicação na estruturação da borda sul e sudoeste do Cráton do São Francisco-Tentativa de um modelo preliminar. In: SIMP. SOBRE O CRÁTON DO SÃO FRANCISCO E SUAS FAIXAS MARGINAIS, 1, 1979, Salvador. Anais... Salvador: Sociedade Brasileira de Geologia/Núcleo Nordeste, 1981. p. 164-168.

ISSN: 2236-837X 